\title{
Higher melatonin in the follicle fluid and MT2 expression in the granulosa cells contribute to the OHSS occurrence
}

\author{
Yiran Li ${ }^{\dagger}$, Lanlan Fang ${ }^{\dagger}$, Yiping Yu, Hao Shi, Sijia Wang, Yanjie Guo and Yingpu Sun ${ }^{*}$
}

\begin{abstract}
Background: Ovarian hyperstimulation syndrome (OHSS) is a common and severe complication for patients undergoing IVF/ICSI-ET. Melatonin widely participates in the regulation of female reproductive endocrine activity. However, whether melatonin participates in the progression of OHSS is largely unknown. This study aims to identify the predictive value of follicular fluid (FF) melatonin for OHSS establishment and the underlying mechanism.

Methods: All participants of this case-control study were enrolled at the Reproductive Medicine Center located in the First Affiliated Hospital of Zhengzhou University in China from January to October in 2017. Quantitative real-time PCR and western blot were used to examine the mRNA and protein levels. Primary granulosa cells were extracted and cultured for in vitro studies. Melatonin concentration was measured by ELISA. Logistic analysis and receiver-operating characteristic (ROC) curves were used to evaluate the predicting value of melatonin on OHSS occurrence.
\end{abstract}

Main outcome measures: The expression level of melatonin receptor 2 (MT2), P450 aromatase cytochrome (aromatase), vascular endothelial growth factor (VEGF), and inducible nitric oxide synthase (iNOS) mRNA in human primary granulosa cells. The concentration of melatonin in FF. The predicting value of melatonin on OHSS and the cutoff value of the prediction.

Results: FF melatonin concentrations were significantly higher in patients with OHSS compared to non-OHSS group $(35.94 \pm 10.18 \mathrm{ng} / \mathrm{mL}$ vs $23.93 \pm 10.94 \mathrm{ng} / \mathrm{mL}, p<0.001)$. The expression of MT2 mRNA $(p=0.0459)$ and protein in granulosa cells was also significantly higher in the OHSS group. When using a cut-off level of $27.52 \mathrm{ng} / \mathrm{ml}$, the sensitivity and specificity of FF melatonin to predict OHSS was 84.6 and $74.0 \%$, respectively $(p<0.0001)$. We also found that melatonin could up-regulates aromatase mRNA, VEGF mRNA expression and down-regulates iNOS mRNA expression in the granulosa cells.

Conclusion: OHSS patients have higher melatonin in the FF as well as higher MT2 expression in the granulosa cells. The melatonin in FF might be used as an effective predictor for the occurrence of OHSS.

Keywords: Melatonin, Melatonin receptor 2, Follicular fluid, Ovarian hyperstimulation syndrome, Controlled ovarian hyperstimulation

\footnotetext{
* Correspondence: syp2008@vip.sina.com

†Yiran Li and Lanlan Fang contributed equally to this work.

Reproductive Medical Center, The First Affiliated Hospital of Zhengzhou

University, 450052 Zhengzhou, People's Republic of ChinaZhengzhou No. 1

construction east roadHe'nan Province, China
}

(c) The Author(s). 2019 Open Access This article is distributed under the terms of the Creative Commons Attribution 4.0 International License (http://creativecommons.org/licenses/by/4.0/), which permits unrestricted use, distribution, and reproduction in any medium, provided you give appropriate credit to the original author(s) and the source, provide a link to the Creative Commons license, and indicate if changes were made. The Creative Commons Public Domain Dedication waiver (http://creativecommons.org/publicdomain/zero/1.0/) applies to the data made available in this article, unless otherwise stated. 


\section{Introduction}

Melatonin (N-acetyl-5-methoxytryptamine) is a compound extracted from pineal glands and peripheral nerve [1]. Its expression is affected by light and dark stimulation, in accordance to circadian rhythm [2]. Previous investigations about melatonin mainly focused on its broad-spectrum free radical scavenging capacity and antioxidant capacity in the reproductive system [3]. Melatonin participates in the regulation of hypothalamic-pituitary-gonadal axis function and reproductive endocrine activity [2, 4]. Melatonin receptor 1 (MT1) and 2 (MT2), belonged to G protein-coupled receptors have been successfully cloned in humans [5-7]. Earlier studies have demonstrated that MT1 and MT2 are widely distributed in the female reproductive system, such as the uterus, ovaries, the epithelial cells of the mammary gland, and the granulosa cells [8]. Furthermore, according to a single-nucleotide polymorphisms (SNP) study, rs10830963 in MT2 gene may predispose the polycystic ovarian syndrome (PCOS) in the Chinese population [9], which indicate that MT2 might regulate follicle development and ovary reactivities. Since the high response and sensibility, the PCOS patients who are under controlled ovarian hyperstimulation $(\mathrm{COH})$ have a higher risk of ovarian hyperstimulation syndrome (OHSS) [10]. In addition to the reproductive system, MT2 has also been found in the blood vessels, potentially allowing melatonin to induce vasodilatation which is the main feature of OHSS $[11,12]$.

OHSS is a common and severe complication for patients who undergo $\mathrm{COH}[13,14]$. Serious complications of OHSS may present as ascites, hydrothorax, electrolyte imbalance, hypovolemic shock and even threatening life [12]. Currently, several factors like rennin angiotensinogen system (RAS), vascular endothelial growth factor (VEGF), interleukins, nitric oxide (NO), tumor necrosis factor (TNF) and estrogens have been identified as causative agents of OHSS $[15,16]$. High level of estrogen and high vascular permeability are the main characteristics of OHSS. As a key rate-limiting enzyme in the transformational process of androgen to estrogen, aromatase can mediate the production of estrogen [17]. While VEGF and $\mathrm{NO}$ can regulate the vascular permeability through angiogenic cytokines and inflammatory factors [18, 19]. In addition, inducible nitric oxide synthase (iNOS) promotes $\mathrm{NO}$ production and activates macrophages to regulate vascular immune inflammation [19, 20]. However, the pathogenesis of OHSS is still not totally illustrated. Thus, how to predict and prevent the occurrence of OHSS at an early stage is still a great challenge.

Recent studies mainly focused on the effects of melatonin on ovarian function and the oocytes [21-25]. The antioxidant effects of melatonin can protect oocytes from the damage of oxidative stress [23]. In addition, the effects of melatonin on the oocytes can be mediated by its receptors [24, 25]. Follicular fluid (FF) melatonin concentrations are highly associated with both quantity and quality of oocytes and the ovarian reserve [26]. While higher ovarian reserve and more retrieved oocytes are high risk factors of OHSS [12]. Considering MT2 has also been found in the blood vessels, potentially allowing melatonin to induce vasodilatation which is the main feature of OHSS, it is hypothesized that melatonin and its receptors participate in the OHSS occurrence. However, the expression and function of melatonin and its receptors in the OHSS are still unknown. Thus, the aims of our present study were to investigate the role of melatonin in the OHSS occurrence and the underlying molecular mechanism. Our study was also designed to test the relationship between FF melatonin and other parameters and whether FF melatonin level could be a potential predictor for the occurrence of OHSS.

\section{Materials and methods Patients}

A total of 57 patients participated in this investigation. All participants enrolled at the Reproductive Medicine Center located in the First Affiliated Hospital of Zhengzhou University in China from January to October in 2017. Study protocols were approved by the Zhengzhou University Research Ethics Board and all participants provided informed consent prior to enrollment. The criteria for included patients were as follows:1) age between 20 and 35; 2) BMI between 18 and $25 \mathrm{~kg} / \mathrm{m}^{2}$; 3) male infertility or tubal infertility; 4) regular menstrual cycles; and 5) without comorbidities such as deranged thyroid function or diabetes. The exclusion criteria were: 1) PCOS, endometriosis or diminished ovarian reserve patients; 2) patients possess hydrosalpinx; 3) patients had a chromosomal abnormality. Patients enrolled in this study were grouped into OHSS or non-OHSS according to their clinical manifestation based on the Golan classification system [27]. Ultimately, a total of 26 OHSS and 31 non-OHSS patients were recruited.

\section{IVF/ICSI-ET protocols}

The standard long protocol for IVF/ICI-ET was treated to all patients. Primarily, gonadotropin-releasing hormone agonist (triptorelin acetate; Ferring AG, Switzerland) was injected for downregulation. Then recombinant $\mathrm{FSH}$ (Gonal-F; Serono, Switzerland) was injected for the ovarian stimulation. The human chorionic gonadotrophin (hCG; Livzon, Guangdong, China) injections were given when a minimum of 3 follicles developed to reach a size of $18 \mathrm{~mm}$. The serum levels of progesterone (P4), luteinizing hormone (LH), estradiol (E2) and hCG were also detected in the morning on the same day. 34 to $36 \mathrm{~h}$ following the hCG administration, oocytes were retrieved 
using transvaginal ultrasound-guided follicular aspiration. At the same day before oocyte retrieval, serum levels of P4 and E2 were also detected.

\section{Follicular fluid collection}

FF was sampled along with oocytes during the oocyte retrieval procedure. All FF samples were collected in a sterile container upon harvesting of the oocytes. Care was taken to ensure that these FF samples that did not contain flushing solution or blood used for analysis. FF were immediately subjected to a 10-min centrifugation at a speed of $2000 \mathrm{rpm}$ before the product was kept at $80{ }^{\circ} \mathrm{C}$ until time of assay.

\section{Human granulosa-lutein cell culture}

Primary human granulosa cells were extracted and purified from the FF aspirates utilizing density centrifugation as previously described [28]. Dulbecco's Modified Eagle Medium/ nutrient mixture F-12 Ham medium (DMEM/F-12; Gibco, Grand Island, NY) supplemented with $10 \%$ charcoal/dextran-treated FBS (HyClone, Logan, UT), $100 \mu \mathrm{g} / \mathrm{mL}$ of streptomycin sulfate and $100 \mathrm{U} / \mathrm{mL}$ of penicillin (Boster, China) was used to culture cells at $37{ }^{\circ} \mathrm{C}$ in a humidified environment comprising of $95 \%$ air and $5 \% \mathrm{CO}_{2}$. For all of experiments involving melatonin treatments, the cells were plated with $1 \mathrm{~mL}$ of culture medium in 12-well plates $(5 \times$ $10^{4}$ cells $/ \mathrm{cm}^{2}$ ). The medium was switched to $0.5 \%$ charcoal/dextran-treated FBS following a 5-day cultivation period. Melatonin (R\&D systems 3550/50, USA) treatments were administered while cells were in this medium. The cells were then left to grow for another $24 \mathrm{~h}$.

\section{Melatonin ELISA assay}

The concentrations of follicular fluid melatonin were determined by melatonin ELISA kits (Abcam213978, UK). All ELISA experiments were run in compliance with the manufacturer's protocol. Melatonin levels were determined as average levels.

\section{Reverse transcription quantitative real-time PCR (RT- qPCR)}

The RNeasy Plus Mini Kit (QIAGEN, Germany) was utilized to extract total cellular RNA following manufacturer's protocols. RNA $(2 \mu \mathrm{g})$ was reverse-transcribed into first-strand cDNA using the GoldScript one-step RT-PCR Kit (Applied Biosystems Grand Island, NY). For qPCR analysis, each sample contained $250 \mathrm{nM}$ of primer, $20 \mathrm{ng}$ of cDNA and 1X SYBR Green PCR Master Mix (Applied Biosystems) to make up a total reaction volume of $20 \mu \mathrm{L}$ per sample. VEGF, AROM, iNOS and GAPDH gene expressions were determined with TaqMan gene expression assays (Applied Biosystems). Three individual experiments were carried out with various cultures, and assays for each sample were performed at least three times. All qPCR analyses were performed on the a 96-well optical reaction plate Applied Biosystems 7500 Real-Time PCR System. qPCR reaction parameters comprised of $2 \mathrm{~min}$ at $50^{\circ} \mathrm{C}$, $10 \mathrm{~min}$ at $95^{\circ} \mathrm{C}$, followed by forty 15 -s long cycles at $95^{\circ}$ $\mathrm{C}$, ending with $1 \mathrm{~min}$ at $60^{\circ} \mathrm{C}$. Primer sequences of utilized primers are as follows: 5'-AAC CAT GAA CTT TCT GCT GTC TTG-3' (sense) and 5' -TTC ACC ACT TCG TGA TGA TTC TG-3' (antisense) for VEGF, 5'-GAG AAT TCA TGC GAG TCT GGA-3' (sense) and 5'-CAT TAT GTG GAA CAT ACT TGA GGA-3' (antisense) for AROM, 5'-ACA AGC CTA CCC CTC CAG AT-3' (sense) and 5'-TCC CGT CAG TTG GTA GGT TCT G-3' (antisense) for iNOS , 5'-CGG AAC GCA GGT AAT TTG TT-3' (sense) and 5'-CCC AGC CGT CAT AGA AGA TG-3' (antisense) for MT2 and 5' -ATG GAA ATC CCA TCA CCA TCT T-3' (sense) and 5'-CGC CCC ACT TGA TTT TGG-3' (antisense) for GAPDH. PCR products were electrophoresed and a dissociation curve analyses were carried out to validate each assay's specificity. Efficiency of each assay was confirmed by determining the amplification efficiency with calibration curves to confirm that the log input amount vs. $\mathrm{Ct}$ value plot had a slope $<|0.1|$. The comparative $\mathrm{Ct}$ (2 $-\Delta \Delta \mathrm{Ct}$ ) method was used to obtain mean mRNA values with values standardized against expression of the GAPDH gene. All experiments were carried out with at least three repeats with the respective cDNA samples.

\section{Western blot}

The PBS was used to wash cells. Then cells were harvested in cell lysis buffer (Cell Signaling Technology). Equal amounts of protein were transferred onto PVDF membranes after separating by SDS polyacrylamide gel electrophoresis. After $1 \mathrm{~h}$ of blocking with 5\% non-fat dry milk in Tris-buffered saline + Tween (TBST), the membranes were incubated overnight at $4{ }^{\circ} \mathrm{C}$ with anti-melatonin receptor $1 \mathrm{~B}$ antibody (Abcam203346, UK) and anti- $\alpha$-tubulin antibody (AT0007, WI), which were diluted in 5\% non-fat milk/TBST. Following primary antibody incubation, the membranes were incubated with the anti-rabbit (Abcam6721, UK) or anti-mouse (Abcam97023, UK) HRP-conjugated secondary antibody. Immunoreactive bands were visualized by an enhanced chemiluminescent substrate (Bio-Rad Laboratories; Shanghai, China). The chemiluminescent blots were imaged by the ChemiDoc MP Imager (Bio-Rad Laboratories).

\section{Statistical analysis}

All data analysis was performed using the SPSS version 21.0 statistical program, with a $p$ value of less than 0.05 deemed to confer statistical significance. Mean \pm standard deviation (SD) was used to present continuous variables that were normally distributed while median (interquartile range) values were used to present variables with highly skewed 
distribution. One-way ANOVA test, Kruskal-Wallis test and the Mann-Whitney $\mathrm{U}$ test were applied onto the data to uncover differences between two groups. The association between FF melatonin concentration and other parameters was measured and tested by Spearman rank correlation coefficients ( $r \mathrm{~s})$. Receiver-operating characteristic (ROC) curves depicting predicted probabilities were generated from logistic regression models of OHSS. The likelihood of OHSS was calculated based on each logistic regression model, which then allowed us to plot stratified ROC curves. Comparisons between ROCs and the area under curves (AUCs) of the models allowed us to determine the presence of differences that were statistically significant.

\section{Results}

Baseline information of included patients

Basic parameters of two groups are described in Table 1. No significant difference was found in age, BMI, antral follicle count (AFC), basal follicle stimulating hormone (FSH), E2, P4, prolactin (PRL) and testosterone (T) levels as well as duration of infertility between OHSS and non-OHSS groups. The starting dose of gonadotrophin, the gonadotrophin duration and total dose of gonadotrophin were not significant different between two groups. Although higher LH levels were found in OHSS group when compared with non-OHSS patients, both of them were in the normal range $(6.81 \pm 5.07$ vs $4.26 \pm 1.67 \mathrm{mIU} /$ $\mathrm{ml}, p=0.020$ ). It is interesting that the serum $\mathrm{E} 2$ and $\mathrm{P} 4$ on the hCG day $(7667.46 \pm 2821.10$ vs $4076.58 \pm 2343.74$ $\mathrm{pg} / \mathrm{ml}, p<0.001 \& 1.10 \pm 0.42$ vs $0.69 \pm 0.33 \mathrm{ng} / \mathrm{ml}, p<$ $0.001)$ and on OPU day $(4306.81 \pm 1683.73$ vs $2402.39 \pm$ $1666.98 \mathrm{pg} / \mathrm{ml}, p<0.001 \& 22.65(11.97-34.61)$ vs 7.28 $(5.37-12.08) \mathrm{ng} / \mathrm{ml}, p<0.001)$ were significant higher in OHSS group. There was no difference of the number of oocytes that larger than $18 \mathrm{~mm}$ before injection between two groups. As expected, the number of total oocytes

Table 1 Comparison of clinical characteristics and IVF outcome between the OHSS and non-OHSS groups

\begin{tabular}{|c|c|c|c|}
\hline Variable & OHSS group $(n=26)$ & Non-OHSS group $(n=31)$ & $P$ value \\
\hline Age of patients $(\mathrm{y})$ & $29.39 \pm 2.56$ & $28.94 \pm 4.04$ & 0.613 \\
\hline $\mathrm{BMI}\left(\mathrm{kg} / \mathrm{m}^{2}\right)$ & $23.25 \pm 2.80$ & $23.40 \pm 2.91$ & 0.842 \\
\hline Infertility duration(y) & $3.62 \pm 2.61$ & $3.81 \pm 2.66$ & 0.786 \\
\hline Basal serum FSH (mIU/ml) & $6.20 \pm 1.10$ & $6.93 \pm 1.76$ & 0.074 \\
\hline Basal serum LH (mlU/ml) & $6.81 \pm 5.07$ & $4.26 \pm 1.67$ & $0.020^{\mathrm{a}}$ \\
\hline Basal serum E2 (pg/ml) & 29.45(21.39-34.61) & 25.02(13.35-39.62) & 0.671 \\
\hline Basal serum P4 (ng/ml) & $0.57(0.38-0.79)$ & $0.54(0.38-0.67)$ & 0.414 \\
\hline Basal serum PRL (ng/ml) & $18.24 \pm 7.56$ & $18.21 \pm 7.94$ & 0.986 \\
\hline Basal serum $T(\mathrm{ng} / \mathrm{ml})$ & $0.31 \pm 0.16$ & $0.25 \pm 0.13$ & 0.279 \\
\hline Antral follicle count(n.) & $16.89 \pm 4.97$ & $13.26 \pm 4.75$ & 0.146 \\
\hline Starting dose of Gonadotrophin (IU) & 150(112.5-150) & 150(112.5-225) & 0.174 \\
\hline Gonadotrophin duration (d) & $11.54 \pm 1.30$ & $10.77 \pm 1.91$ & 0.089 \\
\hline Total Gonadotrophin dose (IU) & $1425.00(1190.63-1678.13)$ & 1500(1275.00-2125.00) & 0.248 \\
\hline Serum E2 on hCG day (pg/ml) & $7667.46 \pm 2821.10$ & $4076.58 \pm 2343.74$ & $<0.001^{\mathrm{a}}$ \\
\hline Serum P4 on hCG day (ng/ml) & $1.10 \pm 0.42$ & $0.69 \pm 0.33$ & $<0.001^{\mathrm{a}}$ \\
\hline Serum E2 on OPU day (pg/ml) & $4306.81 \pm 1683.73$ & $2402.39 \pm 1666.98$ & $<0.001^{\mathrm{a}}$ \\
\hline Serum P4 on OPU day (ng/ml) & $22.65(11.97-34.61)$ & 7.28(5.37-12.08) & $<0.001^{\mathrm{a}}$ \\
\hline Larger than 18 mm before injection (n.) & $4(3-5)$ & $4(3-5.25)$ & 0.201 \\
\hline Total oocytes obtained (n.) & $20.46 \pm 5.83$ & $10.36 \pm 4.87$ & $<0.001^{\mathrm{a}}$ \\
\hline No. of 2PN oocytes & $14.15 \pm 5.49$ & $7.58 \pm 4.07$ & $<0.001^{\mathrm{a}}$ \\
\hline No. of 2PN cleavage embryos & $13.65 \pm 5.11$ & $7.48 \pm 4.12$ & $<0.001^{\mathrm{a}}$ \\
\hline High-quality embryos (n.) & $6.31 \pm 3.00$ & $3.45 \pm 2.50$ & $<0.001^{\mathrm{a}}$ \\
\hline 2PN oocytes ratio & $0.74 \pm 0.04$ & $0.69 \pm 0.03$ & 0.351 \\
\hline 2PN cleavage embryos ratio & $0.72 \pm 0.04$ & $0.67 \pm 0.03$ & 0.32 \\
\hline Total embryos ratio & $0.37 \pm 0.03$ & $0.42 \pm 0.04$ & 0.245 \\
\hline High-quality embryos ratio & $0.35 \pm 0.04$ & $0.32 \pm 0.03$ & 0.596 \\
\hline FF melatonin(ng/ml) & $35.94 \pm 10.18$ & $23.93 \pm 10.94$ & $<0.001^{\mathrm{a}}$ \\
\hline
\end{tabular}

${ }^{\mathrm{a}} P<0.05$ was considered statistically significant 
retrieved (20.46 \pm 5.83 vs10.36 $\pm 4.87, p<0.001)$, the number of $2 \mathrm{PN}$ oocytes $(14.15 \pm 5.49$ vs $7.58 \pm 4.07, p<0.001)$, $2 \mathrm{PN}$ cleavage embryos (13.65 \pm 5.11 vs $7.48 \pm 4.12, p<$ $0.001)$, total embryos obtained $(7.15 \pm 2.80$ vs $4.07 \pm 2.53$, $\mathrm{p}<0.001)$ and high-quality embryos obtained $(6.31 \pm 3.00$ vs $3.45 \pm 2.50, p<0.001$ ) were also significantly higher in OHSS group. While the ratios of these parameters have no differences between two groups.

Patients in the OHSS group showed significantly higher melatonin concentrations which correlated positively with epidemiological parameters

As shown in Table 1 and Fig. 1A, the FF melatonin concentrations on OPU day in the OHSS group were higher when compared to those in the non-OHSS group (35.94 \pm 10.18 $\mathrm{ng} / \mathrm{mL}$ vs $23.93 \pm 10.94 \mathrm{ng} / \mathrm{mL}, p<0.001)$. Figure 1 presents the correlations between FF melatonin concentrations and clinical characteristics of both non-OHSS and OHSS patients. The FF melatonin concentrations were significantly positively correlated with the total number of oocytes retrieved $(\mathrm{r}=$ 0.304, $p=0.0215$, Fig. $1 \mathrm{~B})$, serum E2 levels $(\mathrm{r}=0.3107, p=$ 0.0187, Fig. 1C), and serum P4 levels ( $\mathrm{r}=0.3038, p=0.0216$, Fig. 1D) on the day that patients were given hCG as well as serum E2 levels $(r=0.3198, p=0.0153$, Fig. 1E), and serum P4 levels $(r=0.3245, p=0.0138$, Fig. $1 F)$ on OPU day.

Patients in the OHSS group displayed significantly higher MT2 expression

Human granulosa cells were collected from OHSS and non-OHSS patients and the levels of MT2 mRNA and

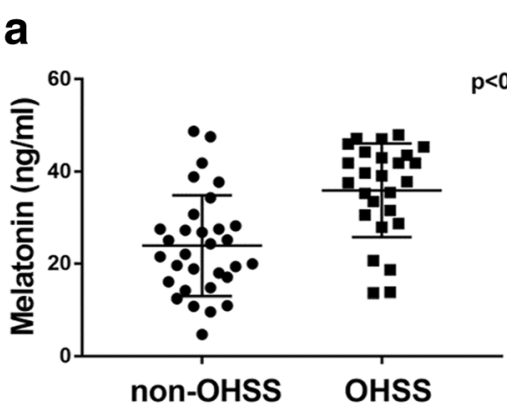

C FF melatonin VS Serum E2 (on hCG day)
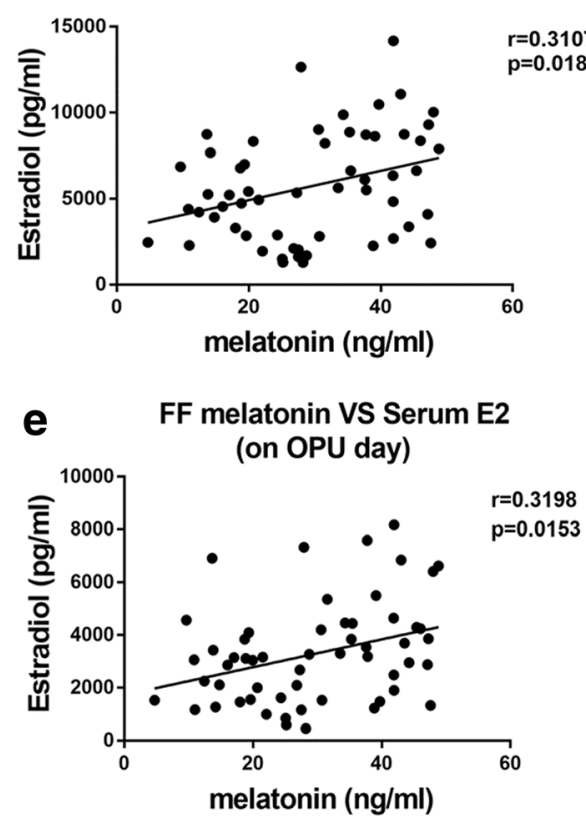

b

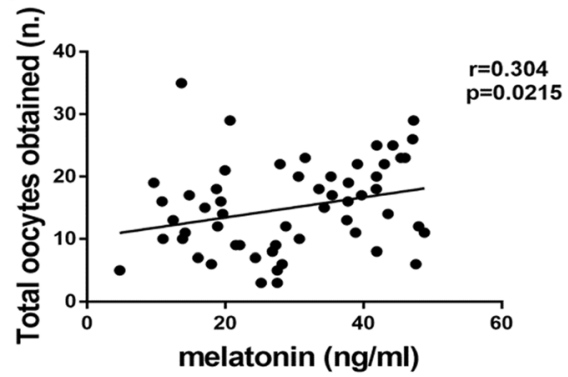

d

FF melatonin VS Serum P4 (on hCG day)

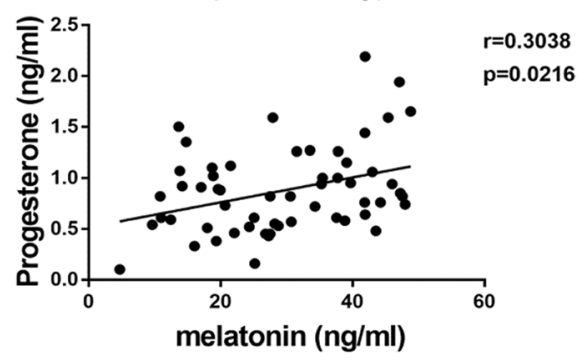

f

FF melatonin VS Serum P4 (on OPU day)

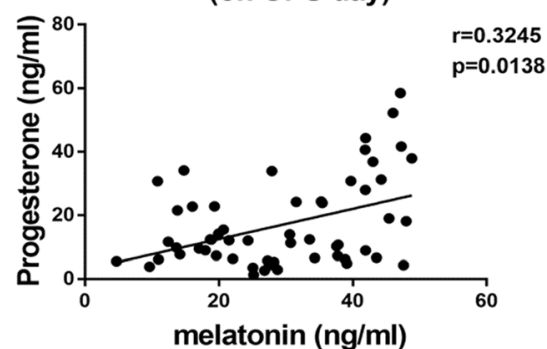

Fig. 1 The difference of melatonin between OHSS and non-OHSS groups and the correlation with epidemiological parameters. (a): The difference of FF melatonin between the OHSS and non-OHSS groups $(p<0.0001)$. (b): Correlation between FF melatonin and the number of total oocytes obtained $(r=0.304 ; p=0.0215)$. (c): Correlation between FF melatonin and serum E2 on the day of hCG administration $(r=0.3107 ; p=0.0187)$. (d): Correlation between FF melatonin and serum P4 on the day of hCG administration $(r=0.3038 ; p=0.0216)$. (e): Correlation between FF melatonin and serum E2 on OPU day $(r=0.3198 ; p=0.0153)$. $(\mathbf{f})$ : Correlation between FF melatonin and serum P4 on OPU day $(r=0.3245 ; p=0.0138)$ 
protein expression were determined by RT-qPCR and western blot respectively. As shown in Fig. 2A and B, the MT2 mRNA was notably higher in the OHSS group $(p=0.0459)$ as well as the protein expression.

\section{Melatonin up-regulates aromatase mRNA and VEGF mRNA expression and down-regulates iNOS mRNA expression}

We treated human granulosa cells with $0.005,0.05$ or 0.5 $\mathrm{mmol} / \mathrm{L}$ melatonin for $24 \mathrm{~h}$, then we measured aromatase, VEGF and iNOS mRNA expression. As shown in Fig. 2, the result indicated that 0.005 or $0.05 \mathrm{mmol} / \mathrm{L}$ melatonin did not affect aromatase, VEGF and iNOS mRNA expression, whereas treatment with $0.5 \mathrm{mmol} / \mathrm{L}$ melatonin could significantly up-regulated aromatase (Fig. 2C) mRNA and VEGF (Fig. 2D) mRNA expression while decreasing iNOS (Fig. 2E) mRNA in human granulosa cells.

\section{The cut-off level of melatonin for the prediction of the} diagnosis of OHSS

Figure 3 and Table 2 both depict the sensitivity and specificity values as predicted by ROC curve analyses. Using a melatonin cut-off level of $27.52 \mathrm{ng} / \mathrm{ml}$, the sensitivity and specificity for melatonin to predict OHSS were 84.6 and $74.0 \%$, respectively $(p<0.0001)$. We further determined a multivariable method for the prediction of OHSS. Our result showed that a model combining melatonin concentration with the E2 level on hCG day and the number of total oocytes obtained get a larger AUC than melatonin ( 0.949 vs $0.785, p=0.0046)$ and serum E2 level on hCG day ( 0.949 vs $0.840, p=0.0297)$, as well as the total oocytes obtained $(0.949$ vs $0.914, p=0.1798)$, alone.

\section{Discussion}

$\mathrm{COH}$ is one of the most important processes in the assisted reproductive technology. During this process, a certain degree of ovarian stimulation is desirable as it can obtain more oocytes. In our study, the OHSS group presented a better outcome of the number of the oocytes and the embryos. However, the ratios of these parameters have no statistical differences. A prospective clinical trial showed that although the differences did not reach statistical significance, the clinical pregnancy rate and implantation rate were in a high tendency in the group treated with melatonin [29]. Thus, it is difficult for us to draw a conclusion whether the high FF melatonin

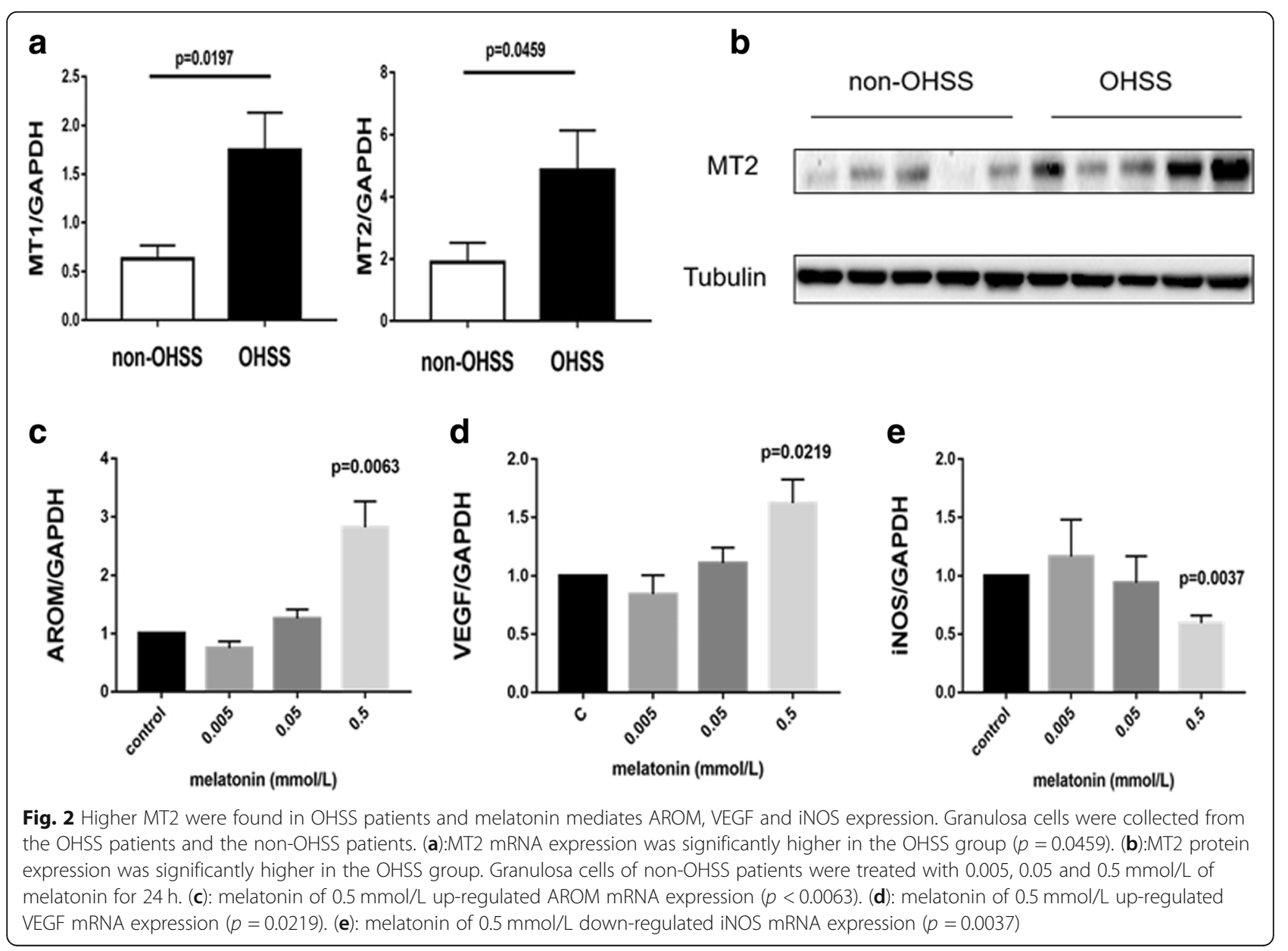




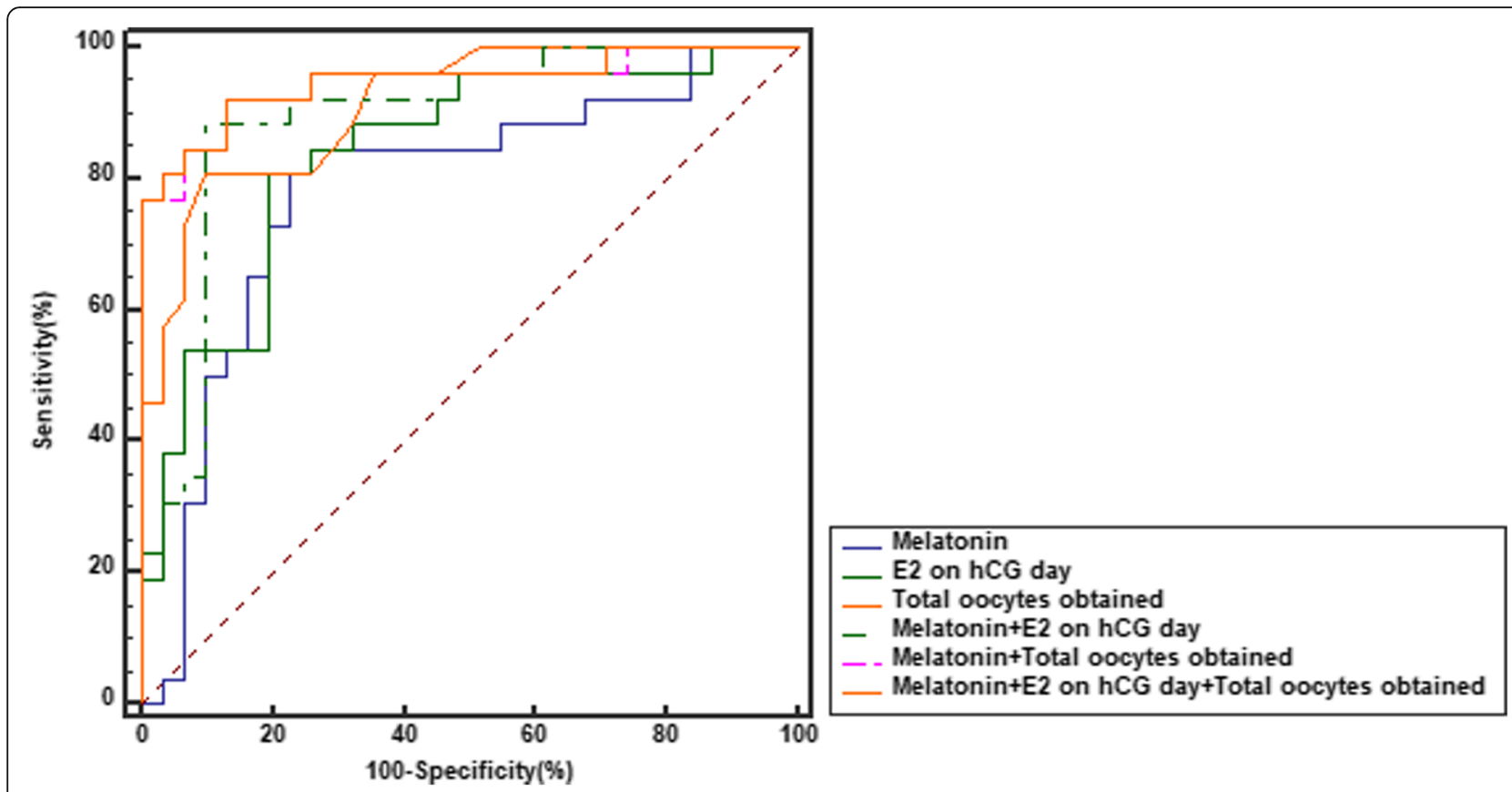

Fig. 3 Comparison of ROC curves. Melatonin in combination with the E2 level on hCG day and the number of total embryos obtained have a bigger AUC than other parameters

concentration is a positive or a negative criterium for the IVF/ICSI outcome. In our study, we compared the FF melatonin concentrations between OHSS and non-OHSS patients and we found that OHSS patients tend to have higher FF melatonin levels. Moreover, the FF melatonin concentrations were found to correlate positively with concentrations of serum E2 and serum P4 both on the hCG day and OPU day. Patients with higher FF melatonin concentrations also retrieved more numbers of oocytes on OPU day. All of these parameters are important indexes to predict the occurrence of OHSS [30]. Thus, the concentration of melatonin in the FF might also be a predictor of OHSS. The ROC curves in our study indicates the potential clinical value of melatonin in predicting OHSS as well.

Ovarian response and follicle fluid microenvironment are reported to be directly correlated with the risk of OHSS. As a biological window during the maturation of oocytes, follicular fluid contains cytokines, hormones, oxidation/antioxidant systems and various metabolites. They form a complex regulatory system to affect the process of OHSS [31]. Interestingly, existing literature shows that the concentration of melatonin in FF is more than three times higher than that in serum [23]. In addition, it was reported that melatonin could improve the maturation and quantity of oocytes [21, 32]. Patients with high ovarian response also had high melatonin concentration [26].

As the largest cell population in the follicle, granulosa cells regulate the growth, development and maturation of follicles in an autocrine and paracrine manner [33]. MT2 has been shown to be closely linked to PCOS and vascular permeability $[9,11]$. In our study, we found that the OHSS patients had higher MT2 expression level in human granulosa cells. This further indicated that melatonin and its receptor were involved in the regulation of OHSS. One of the molecular pathogenesis that melatonin may involve is by increasing aromatase levels to accelerate the conversion

Table 2 The sensitivity and specificity values of ROC curve

\begin{tabular}{|c|c|c|c|c|c|}
\hline Variable & Cut-off & Sensitivity(\%) & Specificity(\%) & $\mathrm{AUC}(\mathrm{Cl})$ & $P$ \\
\hline Melatonin $(\mathrm{ng} / \mathrm{ml})$ & $>27.52$ & 84.6 & 74.2 & $0.785(0.657-0.883)$ & $<0.0001$ \\
\hline E2 on hCG (pg/ml) & $>5420$ & 80.77 & 80.65 & $0.840(0.719-0.924)$ & $<0.0001$ \\
\hline Total oocytes obtained (n.) & $>16$ & 80.8 & 90.3 & $0.914(0.809-0.972)$ & $<0.0001$ \\
\hline Melatonin and E2 on hCG & - & 88.5 & 90.3 & $0.892(0.782-0.959)$ & $<0.0001$ \\
\hline Melatonin and Total oocytes obtained & - & 92.3 & 87.1 & $0.947(0.853-0.989)$ & $<0.0001$ \\
\hline Melatonin, E2 on hCG and Total oocytes obtained & - & 92.3 & 87.1 & $0.949(0.856-0.990)$ & $<0.0001$ \\
\hline
\end{tabular}


of androgen to estrogen in human granulosa cells. Our clinical data which showed that melatonin FF concentrations positively correlated with serum E2 levels measured on the day of hCG injection as well as the OPU day also supported this point. It was widely accepted that both high level of VEGF and low level of NO can increase the permeability of cell membrane, resulting in the occurrence of OHSS $[34,35]$. Previous studies have also confirmed NO can inhibit the production of estrogen, and iNOS can regulate vascular immune inflammation [20,36]. As expected, our results showed that melatonin can up-regulate VEGF expression and down-regulate iNOS expression respectively in the human granulosa cells. This indicated that melatonin probably increased the vascular permeability, leading to the extravasation of body fluids which are responsible for the symptoms observed in OHSS. The regulatory role of melatonin to cells dependents on concentration and cell type [37]. For example, $1 \mathrm{mM}$ melatonin can significantly up-regulated the mRNA expression of $C / E B P \beta$ and $C / E B P \alpha$ in bovine intramuscular preadipocytes (BIPs). While lower melatonin doses were inefficient [38]. In our study, the significant effects of melatonin on aromatase, VEGF and iNOS mRNA expression were only observed when cells were treated with the $0.5 \mathrm{mmol} / \mathrm{L}$ melatonin. Thus the effect of melatonin in vitro may be specific for different types of cells. However, further studies are required to confirm this hypothesis.

The early prevention and diagnosis of OHSS is still a big challenge in $\mathrm{COH}$ process. Presently, several parameters with high sensitivity and specificity for the prediction of OHSS have been identified [39], such as serum E2 concentrations on the day when hCG is injected and the total number of oocytes obtained [40]. In our study, we firstly demonstrated that FF melatonin concentration could be used as a predictor for the occurrence of OHSS. Especially, its predictive power increases when combined with the E2 level on hCG administration day and the number of total oocytes obtained. Our study not only suggests that melatonin may have clinical benefits in the prediction of OHSS, but also indicate that the melatonin can be used as a target for OHSS treatment.

\section{Conclusion}

In our study, we demonstrated for the first time the concentrations of melatonin in follicle fluid are related to the OHSS and could be used as a potential predictor of the OHSS. Furthermore, our results showed treatment with melatonin can regulate the associated factors expression of OHSS. Our study showed melatonin may participate in the occurrence of OHSS. However, further large-scale and prospective investigation are required to validate the use of melatonin in the prediction and prevention of OHSS establishment.

\section{Abbreviations}

AFC: antral follicle count; aromatase: P450 aromatase cytochrome; AUCs: area under curves; $\mathrm{COH}$ : controlled ovarian hyperstimulation; E2: estradiol;

FF: follicle fluid; FSH: follicle stimulating hormone; iNOS: inducible nitric oxide synthase; LH: luteinizing hormone; MT1: melatonin receptor 1;

MT2: melatonin receptor 2; NO: nitric oxide; OHSS: Ovarian hyperstimulation syndrome; P4: progesterone; PCOS: polycystic ovarian syndrome;

PRL: prolactin; r: rank correlation coefficients; RAS: rennin angiotensinogen system; ROC: receiver-operating characteristic; RT-qPCR: Reverse transcription quantitative real-time PCR; SD: standard deviation; SNP: single-nucleotide polymorphisms; T: testosterone; TNF: tumor necrosis factor; VEGF: vascular endothelial growth factor

\section{Acknowledgements}

This study was supported by the Reproductive Medicine Center at the First Affiliated Hospital of Zhengzhou University. We thank the people for their participation in this project.

\section{Funding}

This work was supported by the National Natural Science Foundation of China for Young Scientists (81601253) to Lanlan Fang and an operating grant from the National Natural Science Foundation of China (31471404) to Yingpu Sun. This work was also supported by the specific fund of clinical medical research of Chinese Medical Association (16020160632) and the Foundation from the First Affiliated Hospital of Zhengzhou University for Young Scientists to Lanlan Fang.

\section{Availability of data and materials}

All data supporting the conclusion of this article are included in this published article.

\section{Authors' contribution}

YS, YL and LF were responsible fo the study design, analysis of data and manuscript preparation; LF contributed to the proof reading. YL, YY and SW participated patient recruitment and data collection. SH and $Y G$ participated statistical work. The final manuscript was read and approved by all authors prior to submission.

\section{Ethics approval and consent to participate}

Study protocols were approved by the Zhengzhou University Research Ethics Board and all participants provided informed consent prior to enrollment.

Consent for publication

Not applicable.

\section{Competing interests}

The authors declare that they have no competing interests.

\section{Publisher's Note}

Springer Nature remains neutral with regard to jurisdictional claims in published maps and institutional affiliations.

Received: 15 October 2018 Accepted: 29 March 2019

Published online: 12 April 2019

\section{References}

1. Lerner AB, Case JD, Takahashi Y. Isolation of melatonin and 5methoxyindole-3-acetic acid from bovine pineal glands. J Biol Chem. 1960; 235:1992-7.

2. Malpaux B, Migaud M, Tricoire H, Chemineau P. Biology of mammalian photoperiodism and the critical role of the pineal gland and melatonin. J Biol Rhythm. 2001;16(4):336-47.

3. Cruz MH, Leal CL, Cruz JF, Tan DX, Reiter RJ. Essential actions of melatonin in protecting the ovary from oxidative damage. Theriogenology. 2014;82(7): 925-32.

4. Roy D, Belsham DD. Melatonin receptor activation regulates $\mathrm{GnRH}$ gene expression and secretion in GT1-7 GnRH neurons. Signal transduction mechanisms. J Biol Chem. 2002;277(1):251-8.

5. Ebisawa T, Karne S, Lerner MR, Reppert SM. Expression cloning of a highaffinity melatonin receptor from Xenopus dermal melanophores. Proc Natl Acad Sci U S A. 1994;91(13):6133-7. 
6. Reppert SM, Godson C, Mahle CD, Weaver DR, Slaugenhaupt SA, Gusella JF. Molecular characterization of a second melatonin receptor expressed in human retina and brain: the Mel1b melatonin receptor. Proc Natl Acad Sci U S A. 1995:92(19):8734-8.

7. Dubocovich ML, Rivera-Bermudez MA, Gerdin MJ, Masana MI. Molecular pharmacology, regulation and function of mammalian melatonin receptors. Front Biosci. 2003;8:d1093-108.

8. Tenorio F, Simoes Mde J, Teixeira WW, Teixeira AA. Effects of melatonin and prolactin in reproduction: review of literature. Rev Assoc Med Bras. 2015; 61(3):269-74.

9. Li C, Shi Y, You L, Wang L, Chen ZJ. Association of rs10830963 and rs 10830962 SNPs in the melatonin receptor (MTNR1B) gene among Han Chinese women with polycystic ovary syndrome. Mol Hum Reprod. 2011; 17(3):193-8.

10. $\mathrm{Ng}$ EH, Tang OS, Ho PC. The significance of the number of antral follicles prior to stimulation in predicting ovarian responses in an IVF programme. Hum Reprod. 2000;15(9):1937-42.

11. Masana MI, Doolen S, Ersahin C, Al-Ghoul WM, Duckles SP, Dubocovich ML, Krause DN. MT (2) melatonin receptors are present and functional in rat caudal artery. J Pharmacol Exp Ther. 2002;302(3):1295-302.

12. Practice Committee of the American Society for Reproductive Medicine. Electronic address Aao, practice Committee of the American Society for reproductive $\mathrm{M}$ : prevention and treatment of moderate and severe ovarian hyperstimulation syndrome: a guideline. Fertil Steril. 2016;106(7):1634-47.

13. Steward RG, Lan L, Shah AA, Yeh JS, Price TM, Goldfarb JM, Muasher SJ. Oocyte number as a predictor for ovarian hyperstimulation syndrome and live birth: an analysis of 256,381 in vitro fertilization cycles. Fertil Steril. 2014; 101(4):967-73.

14. Braat DD, Schutte JM, Bernardus RE, Mooij TM, van Leeuwen FE. Maternal death related to IVF in the Netherlands 1984-2008. Hum Reprod. 2010;25(7): 1782-6.

15. Bergh PA, Navot D. Ovarian hyperstimulation syndrome: a review of pathophysiology. J Assist Reprod Genet. 1992;9(5):429-38.

16. Chen CD, Chen HF, Lu HF, Chen SU, Ho HN, Yang YS. Value of serum and follicular fluid cytokine profile in the prediction of moderate to severe ovarian hyperstimulation syndrome. Hum Reprod. 2000;15(5):1037-42.

17. Simpson ER, Mahendroo MS, Means GD, Kilgore MW, Hinshelwood MM, Graham-Lorence S, Amarneh B, Ito Y, Fisher CR, Michael MD, et al. Aromatase cytochrome P450, the enzyme responsible for estrogen biosynthesis. Endocr Rev. 1994;15(3):342-55.

18. Murohara T, Horowitz JR, Silver M, Tsurumi Y, Chen D, Sullivan A, Isner JM. Vascular endothelial growth factor/vascular permeability factor enhances vascular permeability via nitric oxide and prostacyclin. Circulation. 1998; 97(1):99-107.

19. Eu JP, Liu L, Zeng M, Stamler JS. An apoptotic model for nitrosative stress. Biochemistry. 2000;39(5):1040-7.

20. Hansson GK, Hermansson A. The immune system in atherosclerosis. Nat Immunol. 2011;12(3):204-12.

21. Loren $\mathrm{P}$, Sanchez R, Arias ME, Felmer R, Risopatron J, Cheuqueman C. Melatonin scavenger properties against oxidative and Nitrosative stress: impact on gamete handling and in vitro embryo production in humans and other mammals. Int J Mol Sci. 2017;18(6).

22. Tamura H, Takasaki A, Miwa I, Taniguchi K, Maekawa R, Asada H, Taketani T, Matsuoka A, Yamagata Y, Shimamura K, et al. Oxidative stress impairs oocyte quality and melatonin protects oocytes from free radical damage and improves fertilization rate. J Pineal Res. 2008;44(3):280-7.

23. Reiter RJ, Tamura H, Tan DX, Xu XY. Melatonin and the circadian system: contributions to successful female reproduction. Fertil Steril. 2014;102(2): $321-8$.

24. Lee S, Jin JX, Taweechaipaisankul A, Kim GA, Ahn C, Lee BC. Melatonin influences the sonic hedgehog signaling pathway in porcine cumulus oocyte complexes. J Pineal Res. 2017;63(3)

25. Lee S, Jin JX, Taweechaipaisankul A, Kim GA, Lee BC. Stimulatory effects of melatonin on porcine in vitro maturation are mediated by MT2 receptor. Int J Mol Sci. 2018;19(6)

26. Tong J, Sheng S, Sun Y, Li H, Li WP, Zhang C, Chen ZJ. Melatonin levels in follicular fluid as markers for IVF outcomes and predicting ovarian reserve. Reproduction. 2017;153(4):443-51.

27. Golan A, Ron-el R, Herman A, Soffer Y, Weinraub Z, Caspi E. Ovarian hyperstimulation syndrome: an update review. Obstetrical \& gynecological survey. 1989;44(6):430-40.
28. Fang L, Yu Y, Zhang R, He J, Sun YP. Amphiregulin mediates hCG-induced StAR expression and progesterone production in human granulosa cells. Sci Rep. 2016;6:24917

29. Rizzo P, Raffone $\mathrm{E}$, Benedetto $\mathrm{V}$. Effect of the treatment with myo-inositol plus folic acid plus melatonin in comparison with a treatment with myoinositol plus folic acid on oocyte quality and pregnancy outcome in IVF cycles. A prospective, clinical trial. Eur Rev Med Pharmacol Sci. 2010;14(6): 555-61.

30. Aboulghar M. Prediction of ovarian hyperstimulation syndrome (OHSS). Estradiol level has an important role in the prediction of OHSS. Hum Reprod. 2003:18(6):1140-1.

31. Kumar P, Sait SF, Sharma A, Kumar M. Ovarian hyperstimulation syndrome. J Hum Reprod Sci. 2011:4(2):70-5.

32. Friedman OOR, Fisch B, Abir R. In: Acuna-Castroviejo DRI, Escamos G, editors. The importance of melatonin in ovaries of higher mammals. Hauppauge, NY, USA: Nova Science Publishers Inc; 2013. p. 139-61.

33. Matsuda F, Inoue N, Manabe N, Ohkura S. Follicular growth and atresia in mammalian ovaries: regulation by survival and death of granulosa cells. The Journal of reproduction and development. 2012;58(1):44-50.

34. Ludwig M, Jelkmann W, Bauer O, Diedrich K. Prediction of severe ovarian hyperstimulation syndrome by free serum vascular endothelial growth factor concentration on the day of human chorionic gonadotrophin administration. Hum Reprod. 1999;14(10):2437-41.

35. Revel A, Barak V, Lavy Y, Anteby E, Abramov Y, Schenker JJ, Amit A, FinciYeheskel Z, Mayer M, Simon A, et al. Characterization of intraperitoneal cytokines and nitrites in women with severe ovarian hyperstimulation syndrome. Fertil Steril. 1996;66(1):66-71.

36. Tobai $H$, Nishiya I. Nitric oxide mediates inhibitory effect of interleukin-1beta on estrogen production in human granulosa-luteal cells. J Obstet Gynaecol Res. 2001:27(1):53-9.

37. Sainz RM, Mayo JC, Rodriguez C, Tan DX, Lopez-Burillo S, Reiter RJ. Melatonin and cell death: differential actions on apoptosis in normal and cancer cells. Cell Mol Life Sci. 2003;60(7):1407-26.

38. Yang W, Tang K, Wang Y, Zhang Y, Zan L. Melatonin promotes triacylglycerol accumulation via MT2 receptor during differentiation in bovine intramuscular preadipocytes. Sci Rep. 2017;7(1):15080.

39. Kahnberg A, Enskog A, Brannstrom M, Lundin K, Bergh C. Prediction of ovarian hyperstimulation syndrome in women undergoing in vitro fertilization. Acta Obstet Gynecol Scand. 2009;88(12):1373-81.

40. Papanikolaou EG, Pozzobon C, Kolibianakis EM, Camus M, Tournaye H, Fatemi HM, Van Steirteghem A, Devroey P. Incidence and prediction of ovarian hyperstimulation syndrome in women undergoing gonadotropinreleasing hormone antagonist in vitro fertilization cycles. Fertil Steril. 2006; 85(1):112-20.
Ready to submit your research? Choose BMC and benefit from:
- fast, convenient online submission
- thorough peer review by experienced researchers in your field
- rapid publication on acceptance
- support for research data, including large and complex data types
- gold Open Access which fosters wider collaboration and increased citations
- maximum visibility for your research: over 100M website views per year
At BMC, research is always in progress.
Learn more biomedcentral.com/submissions 